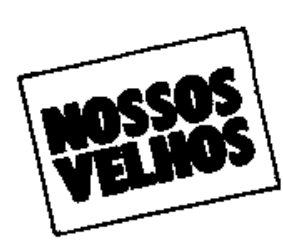

Fomos colher o depoimento de três profissionais que trabalham com os idosos e, tambem, estäo engajados no ensino e na supervisão de trabalhos de Gerontologia.

Raquel Vieira da Cunha e Elvira Abreu e Mello Wagner são psicólogas clínicas, com larga experiência no atendimento aos idosos, e fundadoras do curso de Gerontologia, do Instituto Sedes Sapientiae, que há oito anos vem especializando e aperfeicoando profissionais de todas as áreas.

Liliana Jalfen $\varepsilon$ assistente social, professora do curso de Gerontologia do Sedes Sapientiae, e foi integrante de uma equipe multiprofissional que estava inserida na experiência de atendimento integral, na Argentina.

A seguir, estas três profissionais relatam as suas experiências e os seus modos de encarar o trabalho com os idosos:

Raquel Vieira da Cunha - A velhice não é um conceito que se define somente quando a pessoa faz sessenta anos. Abrange desde a concepção, o nascimento e os primeiros anos de vida, assim como o período de adolescência e de maturidade. Tudo isso vai determinar como será a velhice da pessoa, inclusive se ela vai ou não chegar até a velhice.

Para saber quem é o velho, eu diria que - além das diferenças individuais, culturais e outras - depende da situação a ser levada em conta. Por exemplo, um jogador de futebol já é considerado um velho aos 35 anos. Nós, profissionais liberais, não somos velhos com 60 ou 70 anos. Uma pessoa com 30 anos, que está num lugar onde só tem adolescentes, é velha; quando essa mesma pessoa está com outras que têm 60 anos, sente-se um

\title{
A contribuição dos especialistas
}

jovem. Se perguntarmos para alguém com 70 anos que está vivendo bem, ela dirá que o velho é quem tem 85 anos.

Elvira Abreu e Mello Wagner - O conceito de velhice assim como a definição de velho mudou bastante neste século. No início do século, a expectativa média de vida era de menos de 50 anos; neste final de século, aumentou para 70 anos. Com isso a fase da velhice vai representar uma proporção maior no ciclo de vida. Já não consideramos mais que a pessoa tem um período de crescimento e de maturidade, e depois acabou a vida. Após atingir e viver a plena maturidade, tem ainda um período de vida bastante grande. Os gerontólogos de hoje estão até subdividindo a categoria entre os jovens-velhos, os meio-velhos e os muito-velhos. Não se pode tratat as pessoas nas diferentes etapas da velhice de uma mesma maneira. Por exemplo, a maioria dos muito-velhos tem uma condição de vida extremamente precária e muitas vezes dependem totalmente da assistência de terceiros. Já os jovens-velhos e os meiovelhos estão vivendo $\mathrm{em}$ pleno vigor, tomam parte em todas as atividades $e$ continuam sendo cidadãos participantes na sociedade.

\section{O envelhecimento precoce}

Raquel - Um dos fatores que contribuem muito para acelerar o envelhecimento é a situação econômica precária observada, sobretudo, nos países subdesenvolvidos como o Brasil. As pessoas que pertencem a classes menos privilegiadas já tiveram uma infância subnutrida, viveram em ambientes insalubres e contraíram muitas doenças infecto-contagiosas.
Quando adquiriram essas doenças, não tiveram condiçōes de se tratarem adequadamente, ficando com muito pouca resistência às doenças. Se sobrevivem à infância e à adolescência, vão provavelmente passar a vida adulta exercendo um trabalho muito desgastante. Enfim, essas pessoas levam uma vida com muitos sacrifícios e muito poucas chegam até a velhice. A maioria delas morre antes de atingir a velhice.

Elvira - Por exemplo, um operário, que trabalha na exploração de minérios, está sujeito a condiçōes de trabalho realmente prejudiciais à sua saúde. Os trabalhadores rurais também enfrentam uma situação desgastante. De modo geral, os operários estão submetidos a um ambiente poluído e a condições desfavoráveis no trabalho. Eles têm como consequâência um envelhecimento precoce. Mesmo uma mulher dessa classe, que é dona de casa sobrecarregada de tarefas, também envelhece muito mais precocemente do que as pessoas que têm situação econômica e profissional mais privilegiada.

As pessoas de classe média ou alta não só possuem ocupaçōes menos desgastantes, como também têm acesso aos cuidados e tratamentos necessários. Por isso, a Gerontologia atual não tem como objeto de estudo somente o velho quando este já está em idade mais avançada, mas se dedica a estudar os processos de envelhecimento, que precedem essa idade mais avançada, o que possibilita pensar numa profilaxia deste envelhecimento.

\section{As aposentadorias desiguais}

Elvira - Como é que se sente na 
velhice uma pessoa que vem de uma classe bastante desprotegida, que teve uma gestação sem qualquer assistência, cuja infância foi toda perturbada no seu crescimento biológico, psicológico e social? Como ela vai enfrentar o envelhecimento? Certamente com muito medo, que vai estar presente desde muito cedo na vida dela, porque em geral é um trabalhador empregado que vive sob a ameaça constante de desemprego iminente ou vive mesmo desempregado.

Quando se aposenta, cresce a insegurança na vida dessa pessoa por causa das condições em que se faz a aposentadoria dentro da Consolidação das Leis do Trabalho (CLT) que é completamente diferente da aposentadoria do funcionário público ou do militar. O funcionário público e o militar têm garantidos que o seu ganho de aposentadoria vai ser exatamente o mesmo que a sua classe vai estar recebendo durante o periodo

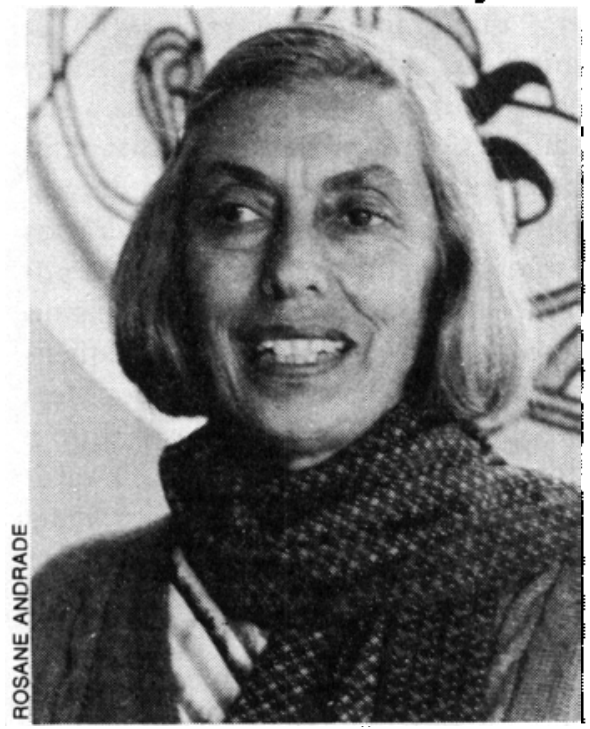

\section{Elvira Wagner}

produtivo. Na medida em que a sua classe vai tendo equiparações salariais, os aposentados também vão sendo contemplados com as mesmas equiparaçōes. A mesma coisa não acontece com o empregado assalariado que é a grande massa dos trabalhadores. Quando se aposenta, já sabe de antemāo que vai passar a receber pouco mais que a metade daquilo que recebia antes. Além disso, vai sofrendo uma perda dos proventos de aposentado a cada ano que passa.

\section{Uma noção \\ distorcida da velhice}

Raquel - Em nossa sociedade, o medo da velhice é justamente o de ficar senil, imóvel e dependente. Temos a idéia de que necessariamente toda pessoa idosa vai ficar acometida pelas doenças crônicas, físicas ou mentais. Mas isso não acontece necessariamente com todos os idosos. E uma porcentagem muito pequena que fica tão gravemente doente. Se fizermos uma avaliação global precoce, podemos muitas vezes tomar medidas para que essas doenças não se desenvolvam tão severa e rapidamente.

Elvira - E verdade. A maioria das pessoas acha que o envelhecimento implica necessariamente deterioração física e mental. Mas isso depende muito do estilo de vida da pessoa. As pessoas que envelhecem bem são as que se adaptam às modificações típicas da idade, à medida que percebem como não são ágeis e nem tão resistentes. Elas sentem que precisam ir mudando a sua maneira de viver, mas sentem também que devem continuar integradas na sociedade.

As pessoas mais jovens, que não têm contato com os mais velhos, fantasiam muito a respeito da velhice. Quando têm um contato constante com os velhos da sua familia, da vizinhança, do ambinte de trabalho, formam uma idéia mais próxima e verossímil da velhice. Têm condições de constatar que a maioria dos velhos são lúcidos, interessados, capazes e desenvolvem uma espécie de sabedoria de vida. Esse contato dos jovens com os mais velhos fornece um modelo positivo de envelhecimento que $\dot{c}$ uma experiência extremamente valiosa para eles não temerem tanto a velhice. Coloca-se também a questão para os proprios jovens: como eles estão se preparando para lidar com a sua própria velhice? É preciso conscientizar que o velho não é só o outro, ele está também no jovem. Com isso promove-se a aproximação das geraçōes.

\section{$O$ contato entre jovens $\mathrm{e}$ idosos}

Raquel - Nos Estados Unidos, tem um programa muito interessante

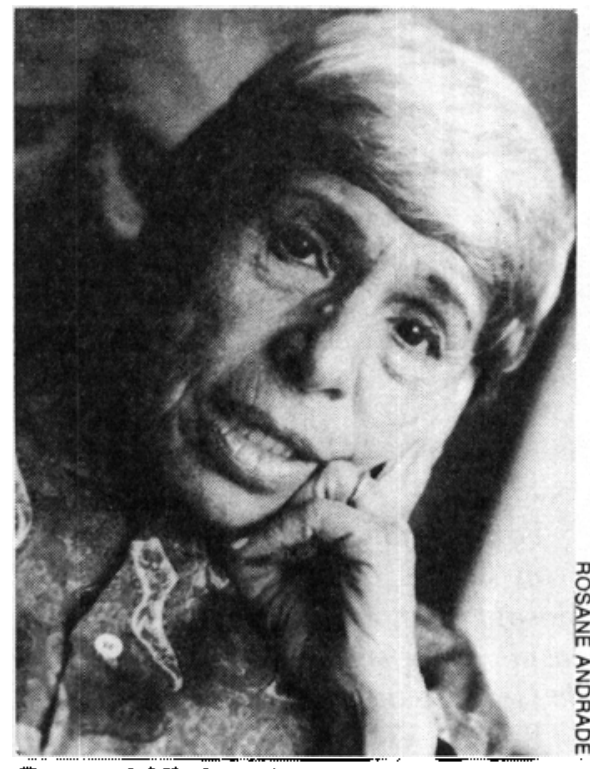

Raquel Vielra da Cunha

que é colocar as pessoas idosas para se relacionarem com as crianças abandonadas. Sob a coordenação de duas psicólogas, os idosos passavam algumas horas da tarde com as crianças. Eram sempre poucas crianças relacionando-se com um idoso. $O$ programa foi muito bem bolado e deu certo. Acho que deveríamos desenvolver programas dessa natureza no Brasil. Nós temos infelizmente tantas crianças abandonadas e carentes de afetos. E também temos muitos idosos que têm muito afeto para dar. Infelizmente, o comportamento do idoso é muitas vezes rabugento, ríspido, por falta de encontrar situaçōes em que possa exteriorizar a sua necessidade de amar e de ser amado. Esse tipo de programa promove o relacionamento intergeracional, mas precisa ser muito bem planejado e coordenado por profissionais, experientes em Gerontologia.

Elvira - Conheci um programa semelhante a esse descrito pela Raquel, também nos Estados Unidos, especificamente no bairro de Brooklin, em New York. O programa previa a possibilidade da meninada do "high school" fazer alguns créditos escolares prestando serviços aos idosos da sua comunidade. Mas não era um programa em que o jovem $e$ o idoso se encontrassem ao acaso. $O$ programa tinha a participação conjunta da equipe multiprofissional, do jovem e do idoso. Durante algumas horas 
semanais, o jovem presta pequenos serviços aos idosos, que estão imobilizados em suas casas, como fazer compras no supermercado, acompanhálos ao médico ou aos exames de laboratório, executar serviços domésticos etc. Como o programa visa à integração, não há rotatividade do jovem e do idoso. Eles formam um par constante e os dois começam a desenvolver de fato uma interaçāo. $O$ idoso começa a se interessar pela vida $e$ pelos valores do jovem e vice-versa. Forma-se uma ligação em que não há somente o caráter imediato de assistência, mas também uma afetividade e um relacionamento de troca.

Raquel - Em todos esses programas, deve existir a possibilidade de se discutir as vivências. Porque às vezes surgem conflitos e, quando esses conflitos são trabalhados, contribuem também para o nosso crescimento; sejamos nós os jovens, a família, o profissional ou o velho.

\section{Uma experiência de} atendimento integral

Liliana Jalfen - Entre 1969 e 73, vivemos na Argentina uma abertura aparentemente democrática. Nessa época, a qualidade de vida eo avanço da ciência tinham gerado ali um grupo de idosos muito significativos. Eram pessoas sadias que continuavam participando na sociedade $e$ constituiam aproximadamente $10 \%$ da população.

Com a data marcada para as eleiçōes após 1969, adotou-se uma política de atendimento integral para aposentados e pensionados, numa tentativa de cooptar votos dessa faixa etária. Criou-se, em 1969/70, o "Instituto Nacional de Jubilados y Pensionados" que possui o objetivo de fornecer a esta população "não-produtiva" um serviço de atendintento nas áreas social e de saúde, por intermédio do seu "Programa de Assistência Médica Integral" (PAMI).

Os PAMIs säo compostos por equipes multiprofissionais que têm como objetivo o atendimento integral ao idoso, abrangendo desde a parte de sáude, que pode ser feita em consultórios, em hospitais ou a domícilio, até a discussão de seu projeto de vida.

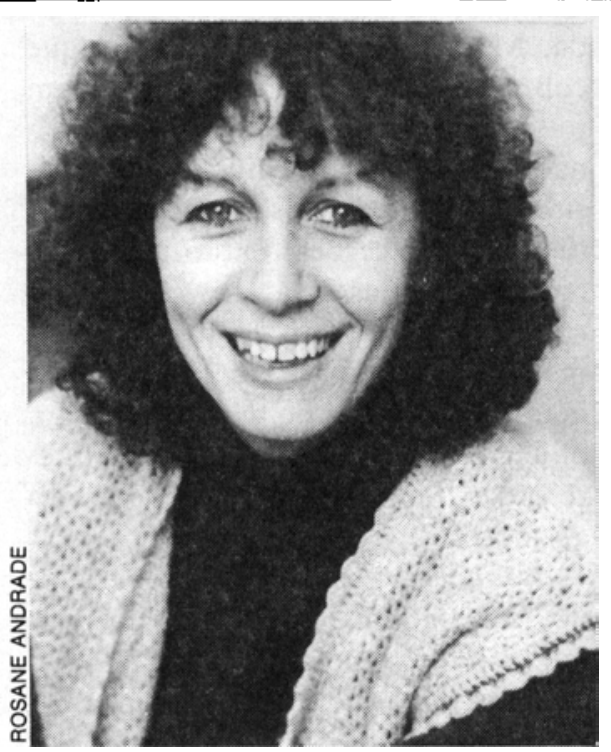

\section{Lillana Jalfon}

E interessante ressaltar que o critério utilizado para os serviços é sempre a regionalização, ou seja, o domicílio do idoso, e por isso os PAMIs encontram-se dispersos por todas as regiôes da cidade.

\section{$O$ acesso aos diversos serviços}

Liliana - Os profissionais médi$\cos$ ou outros especialistas, que atendem em seus consultórios, são contratados pelo Instituto em regime de prestação de serviços e, assim, dão aos idosos a possibilidade de escolher, entre os profissionais cadastrados, os mais próximos de sua residência.

Se for necessário, o serviço conta também com "auxiliares domésticas" que cumprem as funçōes de atendimento no lar para idosos com dificuldades de locomoção, necessitados de repouso temporário, ou que moram sozinhos sem contarem com a atenção de sua família. Estes "auxiliares" dispóem de alguns horários marcados, durante os quais arrumam a casa, controlam a medicação, fazem compras, dão banho ou simplesmente fazem companhia aos idosos.

Cabe assinalar que todos os serviços dos PAMIs podem ser prestados a domicilio, incluindo também o serviço de ambulância gratuito durante as 24 horas. Na compra de próteses e de medicamentos, existem descontos de até $85 \%$.

Neste momento, quase todos os hospitais públicos e privados mantêm um convênio com o Instituto. $E$ oferecido também o serviço funerário para - filiado e sua/seu esposa/o, num convênio firmado com as empresas que fornecem um serviço padrão, podendo este ser alterado pelo pagamento da diferença em caso de o/a filiado/a solicitar.

O Instituto também firmou convênios com asilos, lares e casas de repouso. Os idosos pagam uma porcentagem da sua pensão ou aposentadoria e o resto é pago pelo Instituto, cabendo a este a supervisão do atendimento.

O Instituto conseguiu oferecer o atendimento integral com baixos custos, pois não foi necessário fazer investimentos onerosos em termos de equipamentos ou construções, já que foram utilizados os recursos e infraestruturas existentes a fim de possibilitar a não-marginalização dessa faixa etária.

\section{Por uma política social}

Liliana - Com o passar do tempo, pôde-se verificar que a necessidade dos idosos não se restringia somente aos problemas de saúde e de moradia, mas a solidão, a inexistência de programação cultural e de lazer também se apresentavam como reivindicações urgentes. Foi assim que os PAMIs possibilitaram a organização de grupos comunitários que tiveram um papel importantíssimo no atendimento integral aos idosos.

Atualmente, existe na Argentina uma política social que contempla e reconhece a problemática dos idosos. Um dos recursos oferecidos agora é um serviço de turismo nacional que dá desconto nas passagens, nas hospedagens e nos programas culturais, durante as épocas fora de temporada.

Como sabemos, este tipo de atendimento oferecido na Argentina nāo existe no Brasil e nem se começou a pensar nele, pois a prioridade são os menores de idade, segundo a política governamental brasileira. Eu me pergunto: as crianças, os adolescentes e os adultos não envelhecemos no diaa-dia? Será que continuaremos a esperar um maior agravamento dos pro- 
blemas para nos alertar sobre a importância da prevenção desses problemas?

No Brasil, uma assistência deficiente.

Elvira - Quando uma pessoa de classe menos privilegiada sobrevive a uma idade mais avançada, continua vivendo em geral com a sua família. Mesmo se a família nāo pode tomar conta dos seus velhos como seria desejável, reluta e tenta ficar o máximo possível com seus velhos. Somente procuram um asilo no caso em que não conseguem mais sustentar a situação. No Brasil, os asilos são muito pouco numerosos e são sustentados por colônias de descendentes de imigrantes estrangeiros, como por exemplo, os italianos, os espanhóis, os ingleses, os alemães, os japoneses, os árabes etc. Ou então são sustentados por grupos religiosos que constroem e sustentam os abrigos para idosos.

$O$ governo brasileiro não tem realmente participaçāo efetiva; quando apresenta alguma iniciativa, trata-se somente de algum convênio com esses asilos de entidades civis e religiosas. O governo mesmo não constrói e nem sustenta os asilos. Em nosso país, o Estado não dá a devida importância ao aspecto social. Não cuida de seu cidadão, tanto quanto seria necessário, com programas de saúde, de educaçāo, de lazer, de trabalho. Enfim, o Estado não dá amparo ao trabalhador, que constitui a maior parte da população, para que tenha um nível de vida digno ou pelo menos o mínimo indispensável para viver.

Podemos passar ao extremo oposto dos asilos, que são as chamadas casas de repouso destinadas às classes altas. No momento, elas também não oferecem absolutamente nada daquilo que prometem ou pretendem oferecer. $\mathrm{Na}$ realidade, as casas de repouso são lugares onde as familias mais abastadas encostam os seus idosos e onde não existe um atendimento adequado. Nos asilos, costumam utilizar muito a argumentação de que nảo conseguem pagar os profissionais necessários como médico geriatra, terapeuta ocupacional, psicólogo, assistente social, fisioterapeuta e outros, que dariam uma assistência adequa- da. Mas essas casas de repouso, que cobram bastante caro e lidam com pessoas que têm recursos, também não possuem uma equipe multiprofissional na maioria dos casos, com muito poucas exceções. Então perguntamos por que as casas de repouso não contratam os profissionais? Obviamente, a resposta para nós é que a maioria das casas de repouso tem um objetivo comercial e não estão interessadas no atendimento adequado ao idoso.

Raquel - Agora estão construindo, em algumas cidades grandes como Rio de Janeiro e São Paulo, o "service flat" que é um exemplo trazido da Europa e dos Estados Unidos. E destinado a quem tem muito dinheiro e pode viver sozinho num apartamento de uma maneira independente, sentindo-se protegido porque existe um serviço de enfermagem ou de assistência médica razoável durante 24 horas. A exemplo das casas de repouso, parece que o "service flat" tambem nāo oferece assistência multiprofissional.

Elvira - De modo geral, predomina o ponto de vista de que se a pessoa está bem acomodada num local, tem alimentação e alguma assistência médica, o idoso já estaria bem. Consideram-se somente as necessidades de atendimento físico, as outras necessidades não são pensadas como necessidades das pessoas que envelhecem. A necessidade de lazer, de contato afetivo, de colocar um significado de vida, de ter atividades nas quais possa se sentir integrado na sociedade. Sem isso, a pessoa idosa vai perdendo o ânimo de vida que vem dos contatos e de se sentir realmente participante. No entanto, este objetivo pode ser obtido através de um trabalho pre-

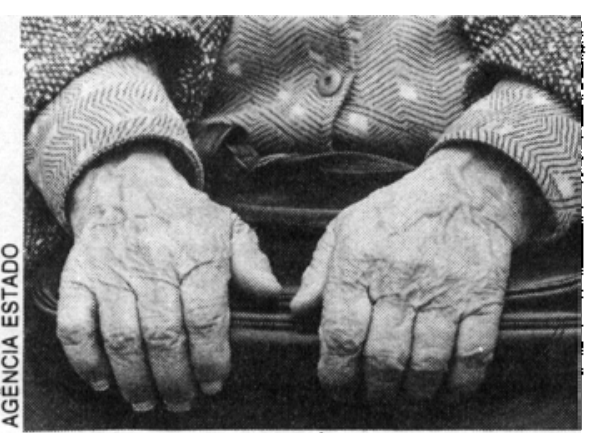

ventivo com as pessoas, na medida em que envelhecem, $e$ da assistência efetiva de uma equipe multiprofissional preparada dentro dos conhecimentos e conceitos da Gerontologia.

\section{A atuaçāo do Psicólogo}

Elvira - O psicólogo tem diversas possibilidades de trabalho numa equipe multiprofissional que lida com os idosos. Este trabalho pode estar relacionado com o atendimento do paciente idoso, com a família do idoso que está sendo atendido e com os integrantes da própria equipe multiprofissional.

Para descrever como é desenvolvido este trabalho, podemos tomar como exemplo a prática das equipes multiprofissionais que já estão im. plantadas no Hospital das Clínicas e no Hospital do Servidor Público Estadual, em Sāo Paulo. Em geral, a clientela dirige-se para estes hospitais porque está basicamente com problemas ou doenças físicas. As equipes multiprofissionais perceberam que, além dos cuidados médicos, os pacientes idosos possuem muitas outras necessidades a serem atendidas. Por exemplo, alguém que sofre do mal de Parkinson, de diabetes, de hipertensão, de problemas respiratórios, articulatórios etc. Esta situação de doença física afeta a pessoa no seu nível psicológico, a sua auto-imagem vai estar modificada, as suas perspectivas de vida mudam.

O psicólogo tem muitos instrumentos de trabalho valiosos para oferecer, desde a triagem, o diagnóstico inicial, a avaliaçāo de acompanhamento e até o trabalho psicoterapêutico. Muitas vezes, as perturbaçōes físicas como perdas ou disfunções metabólicas, problemas hormonais, entre outros, podem falsear um diagnóstico de discúrbio mental. Existe a necessidade considerável de não se dar por satisfeito somente com o diagnóstico inicial. E preciso acompanhar o paciente durante algum tempo posteriormente, a fim de confirmar ou não o diagnóstico. Assim, a discussão na equipe vai ser feita com conhecimento de causa e vai ser possível chegar à melhor forma dessa equipe atuar, assim como indicar o tratamento mais adequado. 
Em geral, os problemas se acentuam com o envelhecimento. Se a pessoa já teve distúrbios neuróticos antes, ela pode vir a apresentar estágios mais comprometidos destes distúrbios, quando nâo foram devidamente tratados. Se apresentou surtos psicóti$\cos$, muito provavelmente vai apresentá-los também na velhice. Nestes casos, a pessoa já deve estar sob cuidados psiquiátricos.

Nos casos de neuroses, pode ser indicado a psicoterapia individual ou os grupos terapêuticos, dependendo da avaliação de cada paciente. Existe a idéia de que, depois de uma fase mais avançada na vida da pessoa, a psicoterapia não alcança ou não surte mais efeito. Essa é uma idćia que ainda existe entre alguns colegas nossos e precisa ser revista. Tanto a Raquel quanto eu somos psicólogas clínicas e temos realizado a psicoterapia de pacientes de meia-idade ou mesmo bem idosos, com os quais os resultados têm sido muito bons. Se o paciente está motivado para lidar com a sua problemática, ele faz psicoterapia e se beneficia muito com isso.

\section{A familia do idoso e a equipe}

Elvira - O trabalho do psicólogo e da equipe com a família do idoso é muito importante na medida em que a pessoa é atendida muitas vezes no ambulatório, mas permanece convivendo com a família. A família precisa de muita orientação no sentido de receber informaçōes a respeito da doença do idoso. Se a família conhece a extensão real dos prejuízos que a doença pode causar, ela vai ajudar adequadamente, colaborando com os medicamentos, alimentação controla$\mathrm{da}$, ajuda no exercício físico etc. Quando isso não acontece, a família atua de maneira desfavorável ao doente. Então, a equipe trabalha para o lado terapêutico e a família trabalha contra esse lado. E não é algo intencional da parte da família, mas feito por uma falta de conhecimento total.

$\mathrm{Na}$ hora em que se consegue uma colaboração dos familiares e eles possuem informaçōes suficientes sobre a doença, o psicólogo pode lidar com os sentimentos que surgem na família por causa da doença do idoso. Podem surgir nos familiares sentimentos como raiva, inveja, ciúmes, conflitos antigos que voltam à tona e outros. Ao serem elaborados estes sentimentos, vai surgindo uma atmosfera mais harmoniosa onde todos os familiares se sentem cuidados.

Un terceira possibilidade do trabatho do psicólogo na equipe multiprofissional é o que envolve os próprios integrantes dessa equipe. Isso porque toda a vez que uma equipe de saúde tem como paciente uma pessoa ou grupo que está vivenciando uma situação extremamente estressante, a própria equipe também vive esse estresse. Os esforços são muito grandes c os resultados pequenos como acontece no caso de algumas afeç̧ōes que vão progressivamente aumentando e, às vezes, caminham para situaçōes bem crônicas ou terminais. O psicólogo pode colaborar com a equipe ajudando os seus integrantes a conviverem melhor ou até superarem este tipo de situação desgastante.

\section{A formação em Gerontologia}

Elvira - Ultimamente tem aumentado o interesse dos profissionais pelo curso de Gerontologia do Instituto Sedes Sapientiae. Alguns deles já estão trabalhando com entidades civis ou órgãos públicos. Às vezes, estes trabalhos não se restringem aos ve-

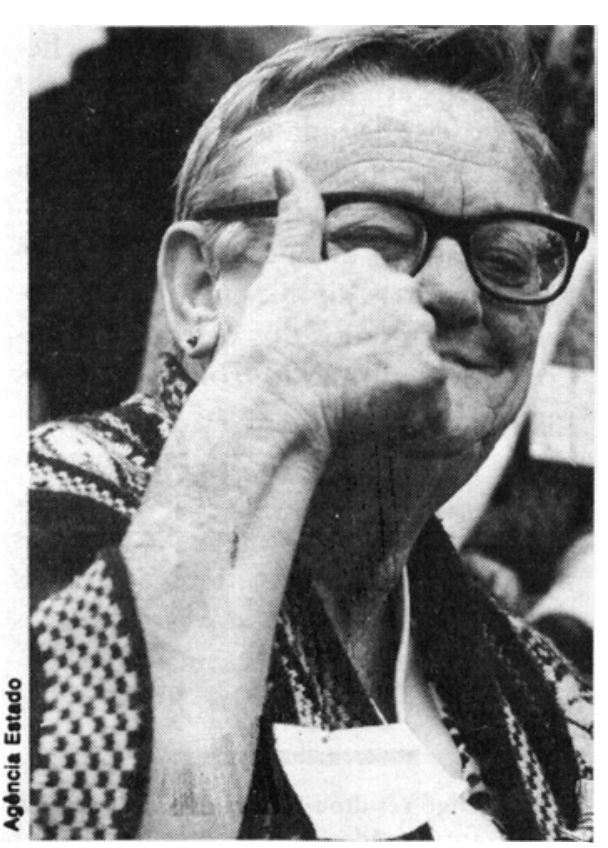

lhos internados nos asilos ou hospitais, mas abrangem a situação ideal que é a de os idosos permanecerem integrados e participantes na sociedade.

Em geral, os nossos alunos são psicólogos, assistentes sociais e outros profissionais de Saúde. Mas o nosso curso está aberto aos profissionais de todas as áreas, sem restrições. Os arquitetos, advogados, engenheiros, jornalistas, economistas, entre outros, raramente se inscrevem no nosso curso e seria desejável que se inscrevessem mais ainda. Os profissionais de todas as áreas profissionais e científicas têm uma contribuição a dar na Gerontologia a partir de sua área especifica.

Nós procuramos dar um embasamento teórico de Gerontologia que abrange os aspectos físicos, psicológicos e sociais dos processos de envelhecimento. Além das aulas, procuramos colocar os alunos em contato direto com as pessoas que envelhecem, com as famílias desses idosos e com as entidades que lidam com eles.

Nāo temos somente a proposta de dar informaçōes teóricas sobre os processos de envelhecimento, também procuramos trabalhar a própria imagem e atitude perante a velhice que os alunos possuem. Consideramos uma condição básica que o profissional se veja, em primeiro lugar, como uma pessoa frente ao envelhecimento que não é só do outro idoso, mas dele também. Pedimos para os alunos desenvolverem trabalhos que os coloquem diretamente em contato com situaçōes envolvendo o envelhecimento,e que são discutidos c claborados em conjunto, nas supervisōes. Sāo trabalhos orientados, práticos, voltados para a nossa realidade e, portanto, eles podem examinar suas próprias reaçōes e atitudes.

O curso de aperfeiçoamento em Gerontologia Social do Instituto Sedes Sapientiae tem a duração de um ano, aberto a profissionais graduados $e m$ todas as faculdades, $e$ as inscriçôes são feitas entre dezembro e janeiro de cada ano. Maiores informaçōes: Rua Ministro Godoy, 1.484, tel. 2628024, em São Paulo. 